\title{
PARFUM PERFECT SOI TIMPURIU DE Salvia sclarea L.
}

\author{
Balmuş Zinaida, Cotelea Ludmila \\ Institutul de Genetică, Fiziologie şi Protecţie a Plantelor, Chişinău, Republica Moldova \\ e-mail: zinaida.balmus@igfpp.md
}

\begin{abstract}
The biological Salvia sclarea L. (sage) is a species with a special economic value, determined by the essential oil that has multiple uses in perfumery, cosmetics, aromatherapy, food, etc. The variety Parfum Perfect is a triple hybrid with constant heterosis. The content of essential oil was determined three times per season through hydro distillation in Ginsberg apparatus and recalculated for dry matter. The production of essential oil in two years of harvesting constitutes $73,5 \mathrm{~kg} / \mathrm{ha}(8,7 \mathrm{~kg} / \mathrm{ha}$ in first year and 64,8 in second year). The variety's efficiency is $3,2 \mathrm{~kg}$ essential oil of per ton of inflorescences.

Key words: Salvia sclarea L., varieties, inflorescence, quantitative characters, vegetation period, essential oil.

\section{Introducere}

Salvia sclarea L.(șerlai) este o specie cu o valoare economică deosebită, determinată de uleiul esențial care are multiple utilizări în parfumerie, cosmetică, aromaterapie, alimentaţie etc. Cultivarea şi procesarea plantelor aromatice şi medicinale pentru menţinerea şi fortificarea sănătăţii sunt în continuă dezvoltare, extindere în ţara noastră $[1,3,9,11,12]$. Genetica și ameliorarea, crearea de soiuri şi hibrizi noi este un proces continuu. Fiecare soi nou omologat, brevetat este mai performant decât cele precedente. Soiurile de provenienţă hibridă create sunt rezultatul multiplelor cercetări pe parcursul a câtorva generaţii de hibrizi, care au servit ca bază în elaborarea soiurilor. Schimbările climatice din ultimele decenii impun cultivarea soiurilor de plante care sunt adaptate la condiţiile de secetă, temperaturilor critice şi ar satisface doleanţele producătorilor $[2,6,7,13]$.

Astfel, în cadrul laboratorului Plante Aromatice și Medicinale investigaţiile în ameliorarea speciei S.sclarea L. sunt axate pe elaborarea materialului genetic cu caractere şi însuşiri noi pentru crearea soiurilor de proveniență hibridă cu productivitate sporită, calitate superioară a uleiului esenţial, datorită concentrației sporite a principiilor active și corelației inedite ale componenților. Soiuri cu termeni diferiți de maturizare, ce ar permite extinderea perioadei de recoltare, procesare a unei cantităţi mai mari de materie primă fără a majora capacitățile industriale de prelucrare.
\end{abstract}

\section{Materiale şi metode}

Materialul biologic include soiuri de provenienţă hibridă create în rezultatul multiplelor cercetări pe parcursul a câtorva generaţii de hibrizi, care au servit ca bază în elaborarea soiurilor. Experienţele au fost amplasate pe lotul experimental al IGFPP. Experienţele au fost montate conform metodicilor validate la şerlai $[8,10,15]$.

Premergător pentru S. sclarea L. au fost culturile cerealiere recoltate pentru boabe. Evaluarea s-a realizat în baza caracterelor care influențează direct productivitatea. Soiul nou a fost evaluat conform cerinţelor CSTSP şi UPOV. Uleiul esenţial s-a separat prin hidrodistilare în aparate Ginsberg [14]. Mostrele de inflorescenţe pentru determinarea conţinutului de ulei esenţial se colectau dimineaţa, între orele 8-10 în perioada de înflorire în masă, când seminţele din verticilele spicului central al inflorescenţei sunt de culoare maronie. Materialul vegetal (100g inflorescență) se mărunțește, apoi introdus în balon cu fundul plat $1000 \mathrm{ml}$ după ce a fost cântărit în prealabil, adăugându-se $200 \mathrm{ml}$ de apă, iar distilarea a durat timp de 60min. Concomitent a fost determinată umiditatea materiei prime a fiecărei mostre. Datele sunt necesare pentru a recalcula conţinutul de ulei esenţial din substanţa proaspătă în substanţă uscată (s.u) şi de-a exclude erorile cauzate de umiditatea diferită a mostrelor. După distilare uleiul esenţial s-a „uscat” $\mathrm{cu} \mathrm{Na} \mathrm{NO}_{4}$ şi s-a păstrat în congelator. Interpretarea statistică a datelor experimentale obținute s-a efectuat conform metodelor în vigoare și cu ajutorul softului STATISTICA 7. 


\section{Rezultate şi discuţii}

Studiile au fost efectuate în experiențele realizate în perioada (2014-2020), având ca obiectiv testarea în CCC a soiurilor de Salvia sclarea L. Soiul timpuriu, Parfum Perfect, este un hibrid triplu cu heterozis constant la un şir de caractere cantitative, inclusiv, conţinutul în ulei esenţial, formula soiului: [( $\left.\left.\mathrm{S}_{3} \times \mathrm{X}-69\right) \mathrm{F}_{2} \mathrm{XS1122} 4 \mathrm{~S}_{3}\right] \mathrm{F}_{12}$, forma maternă a căruia a fost selectată în generaţia $\mathrm{F}_{2}$ a hibridului ( $\mathrm{S}$ $3 \times M-69) F_{2}$, ca forma paternă a fost utilizată linia consangvinizată $\left(S-11224 S_{3}\right)$ derivată de la soiul Crâmskii rannii $[4,5,6]$.

Condițiile pedoclimatice, parametrii de temperatură a aerului și cantitatea depunerilor atmosferice înregistrate în perioada de cercetare au variat de la an la an. O analiză generală a perioadei de referință, evidențiază anii de cercetare 2015,2017,2019, 2020 ca ani extrem de secetoși. Instabilitatea condiţiilor climatice a permis evaluarea obiectivă și multilaterală a soiului nou. În condiţii extremale de dezvoltare soiurile încluse în cercetare au înregistrat rezultate bune. Rezultatele cercetărilor demonstrează, că anii secetoși sunt favorabili culturii șerlaiului prin acumularea și sinteza uleiului esențial. Rezistența sporită la ger și iernare a soiului Parfum Perfect, evaluată în Culturi Comparative de Concurs se exprimă prin numărul de tulpini florale la unitate de suprafaţă în limitele 46,3-53,1 în anul al doilea de vegetaţie.

În baza estimărilor biometrice $\hat{\imath}$ anul $I-\hat{\imath} i$ de vegetaţie s-a constat, că plantele sunt bine dezvoltate, cu talia de peste $125,0 \mathrm{~cm}$ şi au format inflorescenţe lungi de la $52,7 \mathrm{~cm}$ până la $70,0 \mathrm{~cm}$. Inflorescenţele sunt compacte cu $(14,4-16,1)$ ramificaţii de gradul întâi şi $(20,1-25,9)$ ramificaţii de gradul al doilea. Soiul timpuriu, Parfum Perfect în anul întâi de vegetaţie sintezează și acumulează în medie pe sezon $0,935-1,271 \%$ ulei esenţial. Soiul Parfum Perfect asigură producţie de materie primă în limitele 2,17,8 t/ha. În a.2015, în condiţii de secetă plantele au dezvoltat inflorescențe lungi, compacte, rata acestora în masa tulpinii florale fiind de peste $45 \%$, conţinut ridicat de ulei esenţial - 1,049\% (s.u.). Randamentul soiului Parfum Perfect, în anul I-1̂i de vegetaţie (2015), exprimat în producţia de ulei este de 5,9kg/ha.

Tabelul 1. Randamentul soiurilor noi de S. sclarea L. în CCC, doi ani de exploatare a plantaţiei, 3 cicluri (2017-2020)

\begin{tabular}{|c|c|c|c|c|c|c|c|c|c|c|c|c|c|}
\hline \multirow{3}{*}{ Soiul } & \multirow{3}{*}{$\begin{array}{l}\text { Anii } \\
\text { testare }\end{array}$} & \multirow{2}{*}{\multicolumn{3}{|c|}{$\begin{array}{l}\text { Producţia inflores- } \\
\text { cenţe, t/ha }\end{array}$}} & \multicolumn{4}{|c|}{ Conţinutul ulei esenţial } & \multirow{2}{*}{\multicolumn{4}{|c|}{$\begin{array}{l}\text { Producţia de ulei } \\
\text { esenţial, } \mathrm{kg} / \mathrm{ha}\end{array}$}} & \multirow{3}{*}{$\begin{array}{c}\text { Randament: } \\
\mathrm{UE} \mathrm{kg/t} \mathrm{mat.} \\
\text { primă }\end{array}$} \\
\hline & & & & & \multicolumn{2}{|c|}{ s. proaspătă, } & \multicolumn{2}{|c|}{$\%$ (s.u.) } & & & & & \\
\hline & & $\begin{array}{c}\text { Anu } \\
1 \mathrm{I}\end{array}$ & $\begin{array}{c}\text { Anu } \\
\text { lII }\end{array}$ & $\Sigma$ & $\begin{array}{c}\text { Anul } \\
\text { I }\end{array}$ & $\begin{array}{c}\text { Anul } \\
\text { II }\end{array}$ & $\begin{array}{c}\text { Anul } \\
\text { I }\end{array}$ & $\begin{array}{c}\text { Anul } \\
\text { II }\end{array}$ & $\begin{array}{c}\text { Anu } \\
1 \mathrm{I}\end{array}$ & $\begin{array}{l}\text { Anu } \\
1 \text { II }\end{array}$ & $\Sigma$ & $\%$ & \\
\hline \multirow{4}{*}{$\begin{array}{l}\text { Ambra } \\
\text { Plus }\end{array}$} & $2017-2018$ & 11,7 & 11,8 & 23,5 & 0,368 & 0,218 & 1,163 & 0,916 & 43,0 & 25,7 & 68,7 & 100 & 2,9 \\
\hline & 2018-2019 & - & 13,6 & 13,6 & - & 0,249 & 1,104 & 0,907 & - & 33,9 & 33,9 & 100 & 2,5 \\
\hline & $2019-2020$ & 4,3 & 11,9 & 16,2 & 0,398 & 0,314 & 1,139 & 1,051 & 17,1 & 37,4 & 54,5 & 100 & 3,4 \\
\hline & $\mathrm{X}$ & 5,3 & 12,4 & 17,7 & 0,383 & 0,260 & 1,151 & 0,958 & 20,0 & 32,3 & 52,3 & 100 & 2,9 \\
\hline \multirow[t]{4}{*}{ Balsam } & $2017-2018$ & 8,9 & 12,8 & 21,7 & 0,342 & 0,263 & 1,131 & 1,015 & 30,4 & 33,7 & 64,1 & 93,3 & 2,9 \\
\hline & $2018-2019$ & & 16,3 & 16,3 & - & 0,264 & 1,286 & 1,050 & & 43,0 & 43,0 & 126,8 & 2,6 \\
\hline & $2019-2020$ & 6,7 & 12,8 & 19,5 & 0,359 & 0,370 & 1,049 & 1,237 & 24,0 & 47,4 & 71,4 & 131,0 & 3,7 \\
\hline & $\mathrm{X}$ & 5,2 & 14,0 & 19,2 & 0,351 & 0,299 & 1,090 & 1,101 & 18,1 & 41,4 & 59,5 & 113,8 & 3,1 \\
\hline \multirow[t]{4}{*}{ Ambriela } & $2017-2018$ & 8,3 & 11,9 & 20,2 & 0,392 & 0,264 & 1,215 & 1,086 & 32,5 & 31,4 & 63,9 & 93,0 & 3,2 \\
\hline & 2018-2019 & - & 12,7 & 12,7 & - & 0,314 & 1,190 & 1,148 & - & 39,9 & 39,9 & 117,7 & 3,1 \\
\hline & 2019-2020 & 2,3 & 13,1 & 15,4 & 0,314 & 0,426 & 1,134 & 1,320 & 7,2 & 55,8 & 63,0 & 115,6 & 4,1 \\
\hline & $\mathrm{X}$ & 3,5 & 12,6 & 16,1 & 0,353 & 0,335 & 1,175 & 1,185 & 13,2 & 42,4 & 55,6 & 106,3 & 3,5 \\
\hline \multirow{4}{*}{$\begin{array}{l}\text { Parfum } \\
\text { Perfect }\end{array}$} & 2017-2018 & 7,8 & 12,2 & 20,0 & 0,374 & 0,292 & 1,132 & 1,202 & 29,2 & 35,6 & 64,8 & 94,3 & 3,2 \\
\hline & $2018-2019$ & - & 14,2 & 14,2 & - & 0,269 & 0,935 & 1,008 & - & 38,2 & 38,2 & 112,7 & 2,7 \\
\hline & $2019-2020$ & 2,1 & 17,0 & 19,1 & 0,415 & 0,381 & 1,267 & 1,424 & 8,7 & 64,8 & 73,5 & 134,9 & 3,8 \\
\hline & $\mathrm{X}$ & 3,3 & 14,5 & 17,8 & 0,395 & 0,314 & 1,199 & 1,211 & 12,6 & 46,2 & 58,8 & 112,4 & 3,2 \\
\hline
\end{tabular}

Determinând valoarea indicilor caracterelor cantitative la soiul Parfum Perfect, în anul al doilea de vegetaţie putem conclude, că caracterele cantitative au indici destul de buni. Plantele sunt bine dezvoltate, cu talia de peste 120,9-143,2cm, cu inflorescențe lungi, compacte. Raportul dintre talia plantei şi lungimea inflorescenţei fiind foarte avantajos pentru obţinerea unei producţii mari de inflorescenţe.

În doi ani de exploatare a plantaţiei (2014-2015) soiul Parfum Perfect a asigurat cea mai înaltă producţie de inflorescențe $-22,4 \mathrm{t} / \mathrm{ha}$ şi de ulei esențial - 73,1kg/ha. Soiul Parfum Perfect, în a.2016, a asigurat obţinerea unei producţii de materie primă de $8,7 \mathrm{t} / \mathrm{ha}$ şi producţie de ulei esenţial $31,7 \mathrm{~kg} / \mathrm{ha}$ [4]. 
Productivitatea soiului în 2 ani de exploatare a plantaţiei (2017-2018) a fost de 20,0 t/ha materie primă cu conţinut ridicat $(1,132 \%$ ) de ulei esenţial, asigurând obținerea de pe fiecare hectar câte $64,8 \mathrm{~kg} / \mathrm{ha}$ ulei esenţial. Randamentul soiului constituie $3,2 \mathrm{~kg}$ ulei esenţial din o tonă inflorescenţe proaspete (tab.1).

În experienţe integrale 2019-2020 s-au obţinut rezultatele testării soiurilor, care în anul I-îi şi al II-lea de vegetaţie au garantat producţie de materie primă şi ulei esenţial de calitate. Soiurile sunt rezistente la secetă, arşiţă şi au dezvoltat plante cu talia foarte înaltă pentru un an secetos de 103,7-110,0 cm în anul I-îi de vegetaţie şi 109,5-120,6 cm în anul al II-lea de vegetaţie, în funcţie de soi. Soiurile au format inflorescenţe lungi, compacte $(60,6-64,8 \mathrm{~cm})$ în anul I-îi şi $(52,7-58,8 \mathrm{~cm})$ anul al II-lea de vegetaţie. Aceste caractere evident au asigurat soiului Parfum Perfect un conţinut înalt de ulei esenţial: în anul I-îi de la $1,267 \%$ (s.u.) până la 1,424\% (s.u.) anul II-lea de vegetaţie. Producţia de materie primă sumară în 2 ani de exploatare a plantaţiei a constituit 19,1 t/ha (tab.1). Toate soiurile au format producţii înalte de ulei esenţial. Soiul Parfum Perfect în primul an și al doilea de vegetaţie garantează producţie de ulei esenţial de $8,7 \mathrm{~kg} / \mathrm{ha}-64,8 \mathrm{~kg} / \mathrm{ha}$ respectiv (tab.1).

Soiul a fost prezentat la AGEPI, Comisia de Stat pentru Testarea Soiurilor de Plante cu productivitatea de 17,8 t/ha materie primă (inflorescenţe) în 2 ani de exploatare a plantaţiei, cu un conţinut de ulei esenţial înalt, 1,113\% (s.u.) în anul I-îi şi 1,154\% (s.u.) în anul al II-lea de vegetaţie. Producţia sumară de ulei esenţial în 2 ani de exploatare a plantaţiei este de $71,3 \mathrm{~kg} / \mathrm{ha}$. Randamentul soiului nou este foarte înalt: $3,2 \mathrm{~kg}$ ulei esenţial din tona de materie primă. Rezultatele obţinute în CCC au permis brevetarea și omologarea, înregistrarea soiului Parfum Perfect în Catalogul Soiurilor de Plante al Republicii Moldova. Brevet MD 341. Adeverinţă pentru soi de plante Nr.785, 2021[16].

\section{Concluzii}

1. Soiul timpuriu, Parfum Perfect, este un hibrid triplu cu heterozis constant la un şir de caractere cantitative, inclusiv, conţinutul în ulei esenţial, cu formula: [( $\left.\left.\mathrm{S}_{3} \mathrm{xM}-69\right) \mathrm{F}_{2} \mathrm{xS} 11224 \mathrm{~S}_{3}\right] \mathrm{F}_{12}$.

2. Soiul Parfum Perfect acumulaează și sintetizează conţinut în ulei esenţial de la 0,935 \% s.u.) până la $1,424 \%$ (s.u.).

3. Productivitatea soiului în 2 ani de exploatare a plantaţiei variază în limitele 12,2-22,4 t/ha.

4. Soiul Parfum Perfect în 2 ani de exploatare a plantaţiei garantează poducţie de materie primă de pe fiecare hectar de la $38,2 \mathrm{~kg} / \mathrm{ha}$ până la $73,5 \mathrm{~kg} / \mathrm{ha}$ ulei esenţial.

5. Randamentul soiului Parfum Perfect în medie, trei cicluri de dezvoltare constituie $3,2 \mathrm{~kg}$ ulei esenţial din o tonă de inflorescenţe proaspete.

Cercetările au fost realizate în cadrul proiectului Programului de Stat 20.80009.5107.07“Diminuarea consecinţelor schimbărilor climatice prin crearea, implementarea soiurilor de plante medicinale şi aromatice cu productivitate înaltă, rezistente la secetă, iernare, boli, ce asigură dezvoltare sustenabilă a agriculturii, garantează produse de calitate superioară, predestinate industriei de parfumerie, cosmetică, farmaceutică, alimentară”, finanţat de Agenţia Naţională pentru Cercetare şi Dezvoltare.

\section{Bibliografie}

1. BALMUŞ, Z. Cercetări privind crearea şi utilizarea liniilor consangvinizate de Salvia sclarea L.: autoref. al tezei de doctor în şt. agricole. Ch., 2003. 22 p.

2. BALMUŞ, Z. Soiuri de Salvia sclarea L. create şi omologate în Republica Moldova. În: Ştiinţa în Nordul Republicii Moldova: realizări, probleme, perspective: materialele conf. naţ. cu participare intern., Bălţi, 29-30 sept. 2016. Ed. a 2-a. Bălţi: S. n., 2016 Tipogr. Foxtrot, pp. 37-40. ISBN 978-9975-89-029-8.

3. BALMUŞ, Z. Productivitatea soiurilor de Salvia sclarea L. (şerlai). În: Lucrări şt. Univ. Agrară de Stat din Moldova: Ser. Agronomie şi agroecologie. Chişinău, 2018, 52(1), pp. 111-117. [Mat. simpoz. şt. intern. „85 ani ai Facultăţii de Agronomie - realizări şi perspective", dedicat aniv. a 85 de ani de la fondarea Univ. Agrare de Stat din Moldova, 4-6 oct. 2018].

4. BALMUŞ, Z. Parfum Perfect soi nou de Salvia sclarea L. creat în Republica Moldova. Caracteristica hibrizilor de lavandă cu conţinut ridicat de ulei esenţial. În: Biotehnologii avansate - realizări şi perspective: tezele simpoz. şt. intern., 21-22 oct. 2019. Ed. a 5-a. Chişinău, 2019, p. 139. ISBN 978-9975-56-695-7.

5. BALMUŞ, Z., GONCEARIUC, M. Soiuri de S. sclarea L. create în Republica Moldova. In: The $X^{\text {th }}$ international congress of geneticists and breeders, Chisinau, Rep. of Moldova, 28 june-1july 2015: abstract book. Chisinau: Biotehdesign, 2015, p. 73. ISBN 978-9975-933-56 
6. BALMUS, Z., GONCEARIUC, M., COTELEA, L., BUTNARAS, V. Parfum Perfect the new early variety of Salvia sclarea L. (Clary Sage). În: XI International Congress of Geneticists and Breeders from the Republic of Moldova, Chisinau, Republic of Moldova, June 15-16, 2021. Chisinau, 2021, p. 70. ISBN 978-9975-152-136.

7. BALMUŞ, Z., GONCERIUC, M., COTELEA, L., BUTNARAŞ, V. Realizări în ameliorarea speciei Salvia sclarea L. (şerlai) în Republica Moldova. În: Ştiinţa în nordul Republicii Moldova: probleme, realizări, perspective: conferinţa şt. naţ. cu participare intern., consacrată aniv. a 15 ani de la fondarea institutuţiei, Bălţi, 25 26 iunie 2021. Bălţi, 2021. pp. 22-27.

8. GONCEARIUC, M. Metode de ameliorare a speciei Salvia sclarea L. În: Acta Phitoterapica Romanica. A.II, nr.2, 1995, p.12-15.

9. GONCEARIUC, M. 2002, Salvia L., Chişinău, Centrul Ed. al UASM, 212p.

10. GONCEARIUC, M. Şerlaiul. În: Ameliorarea Specială a Plantelor Agricole. Chişinău, 2004, p. 525 -541.

11. GONCEARIUC, M. Salvia sclarea L.. În: Plante medicinale şi aromatice cultivate. Centrul Edit. UASM. 2008, p. 99-120.

12. GONCEARIUC, M.; BALMUŞ Z. Performand new varieties of Salvia sclarea L. wits different period of vegetation carried out in Moldova Republic. Oltenia. Studii şi Comunicări. Ştiinţele Naturii, 2010, 26(1), 9-13, Craiova, România. Pub. Hous Tip. SITECH. P-ISSN: 1454-6914 www.olteniastudii:3xro

13. GONCEARIUC, M., BALMUŞ, Z., COTELEA, L., BUTNARAŞ, V., MAŞCOVŢEVA, S. Influinţa secetei asupra productivităţii soiurilor de Salvia sclarea L. şi Lavandula angustifolia Mill. În: Biodiversitatea în contextul schimbărilor climatic: conf. şt. cu participare intern., 23 noiem. 2018. Ed. a 2-a. Chişinău, 2018, pp. 113116. ISBN 978-9975-3178-9-4.

14. ГИНСБЕРГ, А.С. Урощѐнный способ определения количества эфирного масла в эфироносах. В: Хим.фарм.промышленность, 1932, № 8-9, 1932, с. 326-329.

15. Селекция эфимасличных культур. Методические указания. Симферополь. 1977, стр.69-79.

16. Catalogul Soiurilor de Plante al Republicii Moldova, Ediție Oficială Chişinău, 2021, p. 38. 